\title{
Incidence and Determinants of Acute Diarrhoea in Malaysia: A Population-based Study
}

\author{
K. Gurpreet', G.H. Tee', N.M. Amal'2, R. Paramesarvathy³, and C. Karuthan ${ }^{4}$ \\ 'Institute for Public Health, Ministry of Health, Jalan Bangsar, 50590 Kuala Lumpur, Malaysia, ${ }^{2}$ Institute for Medical Research, \\ Ministry of Health, Jalan Pahang, 50588, Kuala Lumpur, Malaysia, ${ }^{3}$ Kuala Lumpur City Hall, DBKL Tower I, Jalan Raja Laut, 50350, \\ Kuala Lumpur, Malaysia, and ${ }^{4}$ Department of Social and Preventive Medicine, University of Malaya, 50603, Kuala Lumpur, Malaysia
}

\begin{abstract}
Acute diarrhoea is a major health problem in many parts of the world, contributing to about 1.8 million deaths globally. The objectives of the study were to assess the incidence, determinants, and severity of acute diarrhoea in the population. A nation-wide cross-sectional survey involving about 57,000 respondents was conducted via face-to-face interview among eligible respondents of all ages. An acute diarrhoeal episode was defined as having three or more episodes of loose stools in any 24-hour period within the past four weeks before the interview. The severity was measured by duration of acute diarrhoea and associated symptoms. The variables tested as determinants were age, sex, ethnicity, the highest educational level, total monthly household income, and locality. Univariate, bivariate and multivariate procedures meant for complex study design were used in the analyses. The four-week incidence of acute diarrhoea was 5\% [95\% confidence interval (CI) 4.8-5.2]. The incidence of acute diarrhoea among the estimated population was the highest among young adults aged 20-29 years, Other Bumiputras (the pre-dominant ethnic group in East Malaysia), those with tertiary-level of education, those earning a monthly household income of less than RM 400, and rural dwellers. Only age, ethnicity, the highest level of education attained, and locality were significantly associated with acute diarrhoea in bivariate analysis. In multivariate analysis, these four variables were found to be the determinants of acute diarrhoea. Sex and monthly household income were excluded from the model. The mean duration of acute diarrhoea was 2.0 days (standard deviation 1.3). Forty-six percent of the respondents reported stomach cramps as an associated symptom. The findings revealed that acute diarrhoea is still a major public-health concern in Malaysia and grossly undernotified. There is a need for intensification of public-health intervention efforts to reduce the incidence of acute diarrhoea while improving surveillance and notification of the disease.
\end{abstract}

Key words: Cross-sectional survey; Diarrhoea, Acute; Sociodemographic factors; Malaysia

\section{INTRODUCTION}

In many parts of the world, diarrhoea is still a major health problem (1-3). Globally, an estimated 1.8 million people die every year due to diarrhoeal diseases, of whom $90 \%$ are children aged less than five years, mostly in developing countries (4). In lowand middle-income countries, diarrhoeal disease is one of the leading causes of the burden of disease

Correspondence and reprint requests should be addressed to:

Dr. Gurpreet Kaur

Institute for Public Health

Ministry of Health

Jalan Bangsar

50590 Kuala Lumpur

Malaysia

Email: drpreet@yahoo.com

Fax: $+603-22832050$
(1). Even in developed countries, the social and economic impact of diarrhoeal diseases has been shown to be considerable $(5,6)$.

Several countries have conducted populationbased studies on acute diarrhoea to estimate its magnitude and frequency (7-21). In Malaysia (Fig.), while data captured through the public-health surveillance and hospital surveillance systems exist, most studies concentrated on acute diarrhoea among children (22-25). Population-based studies measuring its burden and determinants in the general community are still lacking. Such information is fundamental in the planning and implementation of prevention and management strategies at the community level. In view of this, as part of a 10-yearly nationwide survey by the Ministry of Health on health and morbidity in Malaysia, acute 


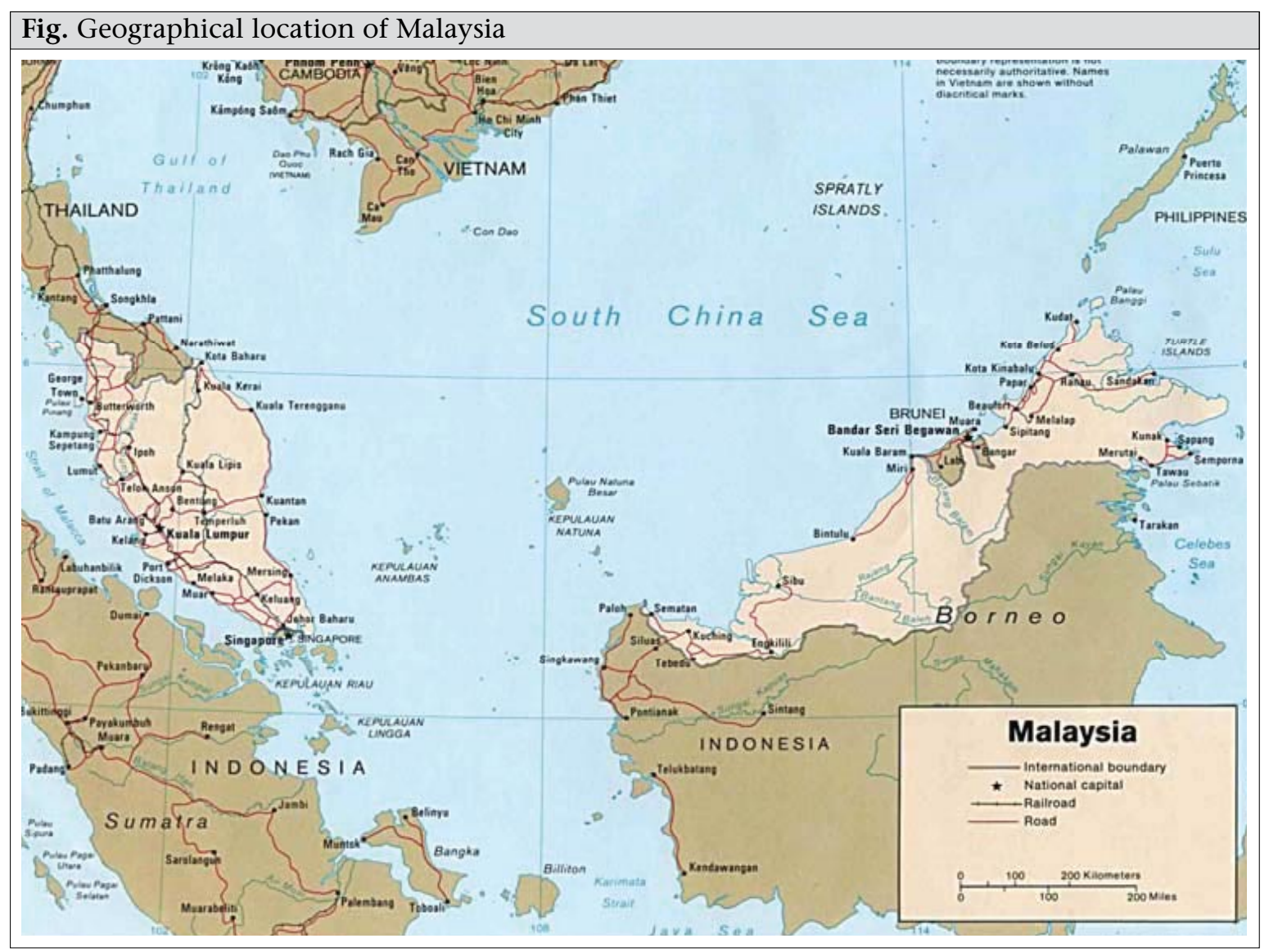

diarrhoea was included as a research topic for the first time.

The general objective of the study was to determine the incidence of acute diarrhoea while the specific objectives were to determine the sociodemographic factors associated with acute diarrhoea, its predictors and to determine the severity of acute diarrhoea in the Malaysian population.

\section{MATERIALS AND METHODS}

\section{Study design}

This study was part of a nationwide cross-sectional community household interview survey, specifically known as the Third National Health and Morbidity Survey (NHMS III) (26). It was conducted throughout Malaysia from April to mid-August 2006. In total, 2,150 enumeration blocks (EBs) and 17,251 living quarters (LQs) were selected using a two-stage stratified random sampling method by the Department of Statistics Malaysia. All eligible persons in the household, who gave written consent, regardless of age, were interviewed. For children aged 12 years and below, the mother or guardian was interviewed on behalf of the child. The survey instrument for the acute diarrhoea module was a structured, pretested and piloted question- naire administered via a face-to-face interview by trained interviewers comprising public-health nurses from the Ministry of Health and part-time recruits.

\section{Operational definition}

Acute diarrhoea was defined as a self-reported episode of acute diarrhoea, i.e. having three or more episodes of loose stools in any 24-hour period within the past four weeks (28 days) before the interview. The definition excludes any type of chronic diarrhoea already experienced by the respondent as a result of the underlying diseases, such as cancer of the bowel, ulcerative colitis, or Crohn's disease.

Since the duration of an episode of acute diarrhoea is short, lasting usually a few days and rarely more than a week, an assumption for statistical analyses was made that each case of acute diarrhoea contributed to only one new episode of acute diarrhoea in the preceding four weeks of the interview. Since a person can acquire multiple episodes of acute diarrhoea in a year, the incidence of acute diarrhoea per person per year was also estimated (calculated from the estimated number of episodes annually divided by the total population for the year). Other assumptions made were that the incidence 
of acute diarrhoea and the population at risk were relatively stable throughout the year. The reference population was the 2006 projected population by the Department of Statistics Malaysia.

The severity of acute diarrhoea was measured by two parameters, namely the duration of diarrhoea as defined by the number of days the respondent experienced diarrhoea and the association of any other symptom(s), along with diarrhoea, such as fever, vomiting, stomach cramps, and blood in stools.

\section{Analysis of data}

Appropriate quality-control measures were implemented at all levels of the survey from the field to the operations rooms to maximize response rate and completeness of data. Data were entered into a web-based database using double-entry method to minimize errors. Analyses of cleaned data were performed using the Complex Samples add-on module in the SPSS software (version 16) (27). For the purpose of analyses, non-respondents were those who had answered other sections of the questionnaire but not the module on acute diarrhoea. Respondents with a 'do not know' or missing answers were excluded from analyses.

\section{Ethical approval}

The Medical Research Ethics Committee of the Ministry of Health approved the study.

\section{RESULTS}

In total, 15,519 LQs were successfully visited giving an LQ sampling unit response rate of $90 \%$. The response rate for this module from 56,710 eligible respondents representing $21,095,810$ people on weighted counts was $98.3 \%$.

The majority of the respondents comprised children and young adults aged 29 years and below (55.3\%), females (52.9\%), and Malays (57.4\%). About 58\% of the respondents were urban residents, and $62 \%$ had a household income of RM 1,999 or below. About 45\% had attained a highest level of secondary education (Table 1 ).

\section{Incidence of acute diarrhoea}

Overall, the incidence of self-reported acute diarrhoea within a four-week period in the Malaysian population was 5\% [95\% confidence interval (CI) 4.8-5.2] or 1,036,518 episodes (95\% CI 985, 935$1,087,100)$ in the weighted population. This translates to $13,474,728$ (95\% CI 12,875,828-14,099,955) episodes of acute diarrhoea annually. The distribution of incidence of acute diarrhoea by sociodemographic characteristics is shown in Table 2.

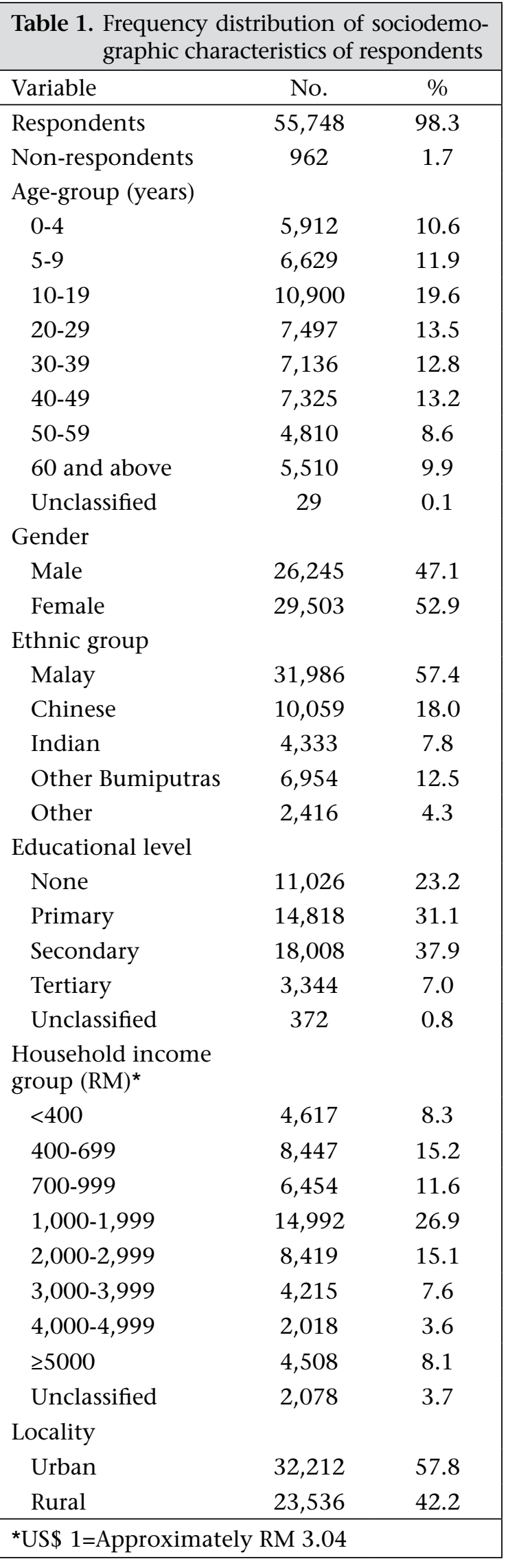




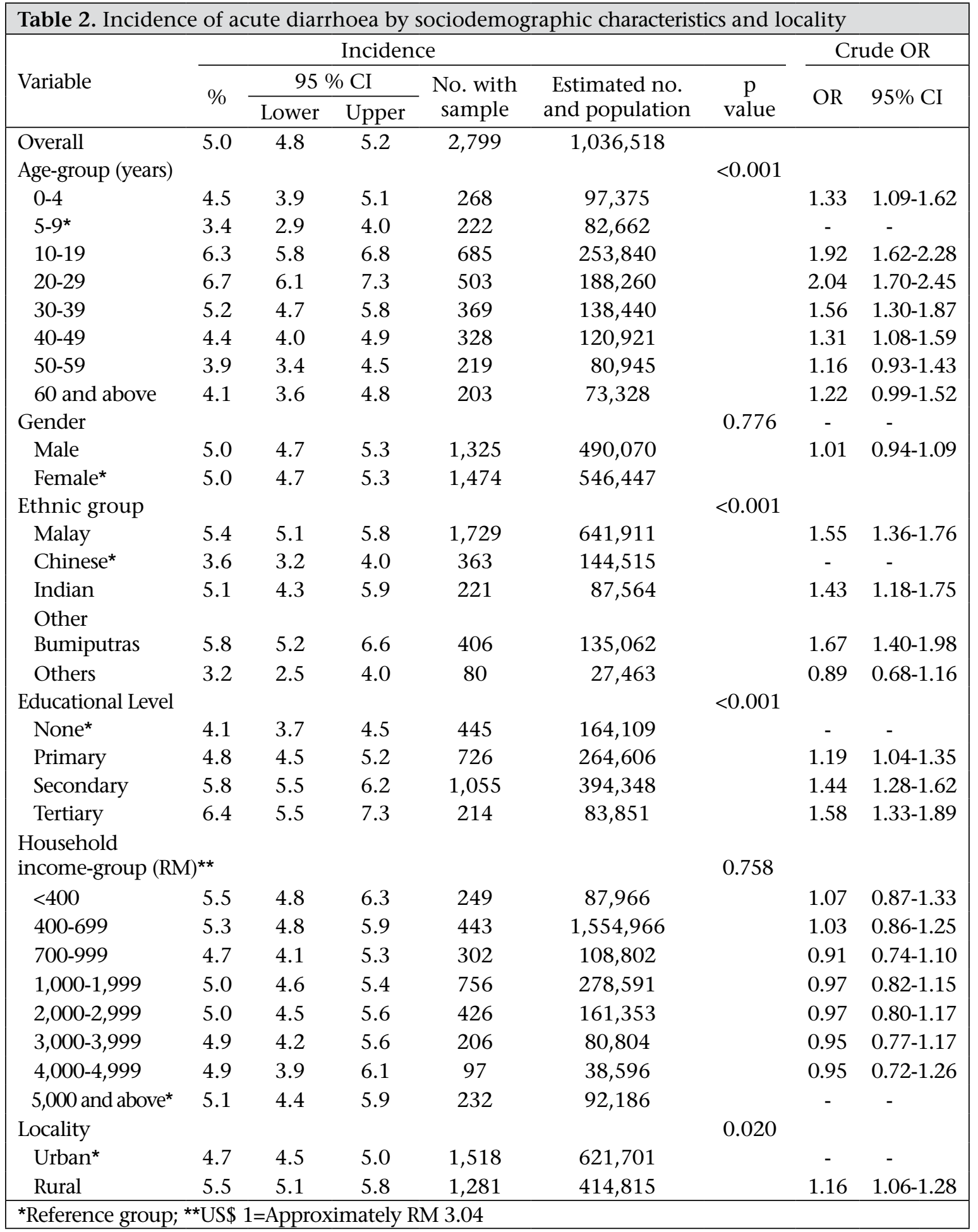

Incidence of acute diarrhoea by sociodemographic profile

By age-group, the four-week incidence of acute diarrhoea was the highest among young adults aged 20-29 years (6.7\%, 95\% CI 6.1-7.3). By ethnicity, Other Bumiputras (the predominant ethnic group in East Malaysia) recorded the highest level of inci- dence $(5.8 \%, 95 \%$ CI 5.2-6.6). By the highest educational level, those with tertiary education ranked the highest in the incidence of acute diarrhoea (6.4\%, 95\% CI 5.5-7.3). Those with less than RM 400 per month in household income showed the highest level of incidence (5.5\%, 95\% CI 4.8-6.3). Those residing in rural areas had a higher level of 


\begin{tabular}{|c|c|c|c|}
\hline Variable & $\begin{array}{l}\text { Adjusted } \\
\text { OR }\end{array}$ & $95 \% \mathrm{CI}$ & $\begin{array}{c}\mathrm{p} \\
\text { value }\end{array}$ \\
\hline $\begin{array}{l}\text { Age-group } \\
\text { (years) }\end{array}$ & & & 0.000 \\
\hline $0-4$ & 1.44 & $1.11-1.87$ & \\
\hline $5-9^{*}$ & - & - & \\
\hline $10-19$ & 1.56 & $1.26-1.93$ & \\
\hline $20-29$ & 1.47 & $1.14-1.89$ & \\
\hline $30-39$ & 1.16 & $0.90-1.50$ & \\
\hline $40-49$ & 1.00 & $0.78-1.28$ & \\
\hline $50-59$ & 0.93 & $0.71-1.21$ & \\
\hline 60 above & 1.09 & $0.84-1.41$ & \\
\hline Ethnic group & & & 0.000 \\
\hline Malay & 1.48 & $1.29-1.70$ & \\
\hline Chinese $^{*}$ & - & - & \\
\hline Indian & 1.41 & $1.15-1.71$ & \\
\hline Other & & & \\
\hline Bumiputras & 1.62 & $1.36-1.94$ & \\
\hline Others & 0.83 & $0.63-1.10$ & \\
\hline $\begin{array}{l}\text { Educational } \\
\text { level }\end{array}$ & & & 0.000 \\
\hline None $^{*}$ & - & - & \\
\hline Primary & 1.20 & $1.04-1.39$ & \\
\hline Secondary & 1.39 & $1.20-1.61$ & \\
\hline Tertiary & 1.63 & $1.33-2.00$ & \\
\hline $\begin{array}{l}\text { Not } \\
\text { applicable } \\
(0-4 \text { years }\end{array}$ & & & \\
\hline old) & 0.89 & $0.683-1.17$ & \\
\hline Locality & & & 0.043 \\
\hline Urban* & - & & \\
\hline Rural & 1.11 & $1.00-1.23$ & \\
\hline \multicolumn{4}{|c|}{$\begin{array}{l}\text { Gender and monthly household income were } \\
\text { removed sequentially from the final model as } \\
\text { these did not contribute significantly to the } \\
\text { model (p }>0.1 \text { ). *Reference group; CI=Confidence } \\
\text { interval; OR=Odds ratio }\end{array}$} \\
\hline
\end{tabular}

incidence of acute diarrhoea (5.5\%, 95\% CI 5.1-5.8) than urban dwellers. The males and females had the same level of incidence (5\%, 95\% CI 4.7-5.3).

\section{Bivariate analyses}

Except for gender and household income, all other variables were significantly associated with acute diarrhoea (Table 2). Compared to respondents aged 5-9 years, respondents in all age-groups, except for those aged 50-59 and 60 years and above, were more likely to experience acute diarrhoea. The Malays, Indians, and Other Bumiputras were more likely to report acute diarrhoea than the Chinese.
As the educational level increased from primary to tertiary, the likelihood of acute diarrhoea also increased steadily when compared with the reference group. Rural residents were 1.2 times more likely to report acute diarrhoea compared to urban residents.

\section{Multivariate analyses}

Multivariate analyses were carried out to identify the determinants of acute diarrhoea. All the variables (age, gender, race, the highest educational level, household income, and locality) were initially included into the model. To obtain a parsimonious model, insignificant variables were removed one at a time, and only variables with a $p$ value of $<0.10$ was retained. Only age, ethnicity, the highest educational level attained, and locality were the significant determinants in the final model (Table 3 ). Based on the adjusted odds ratio (AOR), those in the age-group of $10-19$ years were 1.56 (95\% CI 1.26-1.93) times more likely and those in the agegroup of 20-29 years were 1.47 (95\% CI 1.14-1.89) times more likely to experience acute diarrhoea compared to those in the age-group of 5-9 years. The Malays, Indians, and Other Bumiputras were 1.48 (95\% CI 1.29-1.70), 1.41 (95\% CI 1.15-1.71), and 1.62 (95\% CI 1.36-1.94) times more likely to experience acute diarrhoea respectively compared to the Chinese. Compared to those with no formal education, the likelihood of acute diarrhoea among those with primary, secondary and tertiary education was 1.20 (95\% CI 1.04-1.39), 1.39 (95\% CI 1.20-1.61), and 1.63 (95\% CI 1.33-2.00) respectively. Rural dwellers were only marginally (1.1 times) more likely to experience acute diarrhoea compared to urban dwellers $(\mathrm{AOR}=1.11,95 \% \mathrm{CI}$ 1.00-1.23).

\section{Duration of acute diarrhoea}

The duration of acute diarrhoea in the population ranged from one day to seven days. The mean duration was 2.0 days (95\% CI 1.9-2.1) (Table 4). More than one-third of the population experienced diarrhoea for only one day $(42.2 \%$; $95 \%$ CI 40.2-44.2) and two days (35.0\%, 95\% CI 33.1-36.9) respectively. Less than $4 \%$ experienced acute diarrhoea from four days to one week.

The longest mean duration of 2.7 days (95\% CI 2.4-2.9) was observed among young children and infants. The mean duration of acute diarrhoea declined steadily among persons aged 5-49 years, with adults aged 40-49 years experiencing the shortest duration of 1.8 days (95\% CI 1.6-1.9). From ages 50 years onward, the mean duration of acute diarrhoea was similar to that in older children and teens 


\begin{tabular}{|c|c|c|c|}
\hline Variable & $\begin{array}{c}\text { Mean } \\
\text { duration } \\
\text { (days) }\end{array}$ & $95 \% \mathrm{CI}$ & $\begin{array}{c}\mathrm{p} \\
\text { value }\end{array}$ \\
\hline Overall & 2.0 & $1.9-2.1$ & - \\
\hline $\begin{array}{l}\text { Age-group } \\
\text { (years) }\end{array}$ & & & $<0.001$ \\
\hline $0-4$ & 2.7 & $2.4-2.9$ & \\
\hline $5-9$ & 2.1 & $1.9-2.4$ & \\
\hline $10-19$ & 2.0 & $1.9-2.1$ & \\
\hline $20-29$ & 1.9 & $1.8-2.0$ & \\
\hline $30-39$ & 1.8 & $1.7-2.0$ & \\
\hline $40-49$ & 1.8 & $1.6-1.9$ & \\
\hline $50-59$ & 2.1 & $1.9-2.2$ & \\
\hline 60 and above & 2.0 & $1.8-2.1$ & \\
\hline Gender & & & 0.042 \\
\hline Male & 2.0 & $1.9-2.0$ & \\
\hline Female & 2.1 & $2.0-2.1$ & \\
\hline Ethnicity & & & $<0.001$ \\
\hline Malay & 2.0 & $1.9-2.1$ & \\
\hline Chinese & 1.8 & $1.7-1.9$ & \\
\hline Indian & 2.1 & $2.0-2.3$ & \\
\hline Other & & & \\
\hline Bumiputras & 2.2 & $2.0-2.4$ & \\
\hline Others & 2.5 & $2.1-2.8$ & \\
\hline $\begin{array}{l}\text { Educational } \\
\text { level }\end{array}$ & & & $<0.001$ \\
\hline None & 2.1 & $1.9-2.2$ & \\
\hline Primary & 2.0 & $1.9-2.1$ & \\
\hline Secondary & 1.9 & $1.8-2.0$ & \\
\hline Tertiary & 1.6 & $1.5-1.7$ & \\
\hline $\begin{array}{l}\text { Household } \\
\text { income }(\mathrm{RM}) *\end{array}$ & & & $<0.001$ \\
\hline$<400$ & 2.1 & $2.0-2.3$ & \\
\hline $400-699$ & 2.1 & $2.0-2.3$ & \\
\hline $700-999$ & 2.3 & $2.1-2.5$ & \\
\hline $1,000-1,999$ & 2.0 & $1.9-2.0$ & \\
\hline $2,000-2,999$ & 2.0 & $1.9-2.2$ & \\
\hline $3,000-3,999$ & 1.8 & $1.6-1.9$ & \\
\hline $4,000-4,999$ & 1.9 & $1.6-2.2$ & \\
\hline $\begin{array}{l}5,000 \text { and } \\
\text { above }\end{array}$ & 1.8 & $1.6-1.9$ & \\
\hline Locality & & & 0.036 \\
\hline Urban & 2.0 & $1.9-2.0$ & \\
\hline Rural & 2.1 & $2.0-2.2$ & \\
\hline \multicolumn{4}{|c|}{$\begin{array}{l}\text { *US\$ } 1=\text { Approximately RM 3.04. CI=Confidence } \\
\text { interval }\end{array}$} \\
\hline
\end{tabular}

(Table 4). Women, other races, those without any formal education, those with a monthly household income of RM 700-999, and rural residents had the longest mean duration of acute diarrhoea (2.1-2.5 days; 95\% CI 2.0-2.8).

\section{Associated symptoms}

Abdominal cramp was the commonest symptom among those with acute diarrhoea. About $16 \%$ of the affected people complained of having vomiting or fever each (95\% CI 14.6-17.5 and 14.4-17.5 respectively) while only 3.5\% (95\% CI 2.9-4.3) had dysentery. About $43 \%$ had acute diarrhoea without any other associated symptoms, such as fever, vomiting, or blood in stool.

\section{DISCUSSION}

The study was the first nationwide population survey to obtain baseline estimates of acute diarrhoea in the community. The four-week incidence rate of acute diarrhoea of 5\% in our study is comparable with the estimates by Scallan et al. in a study comparing Australia, Canada, Ireland, and the USA (16). The incidence was 7.6\% in both Canada and USA, 6.4\% in Australia, and 3.4\% in Ireland. Although the response rates differed in that study, the use of a standard definition and the method of interview allow for comparison of the estimates among the four countries. Another study in Ireland found the incidence similar to our study at $4.5 \%$ (28). Hall et al. also found a similar estimate of $7 \%$ for infectious gastrointestinal illness among respondents in Australia (15). In contrast, other studies in the USA $(10,11)$ (July 1996-June 1997 and July 1998-June 1999), Canada $(13,14,19)$, Queensland (29), and Cuba (8) found much higher estimates (8.6-15.5\%) of acute diarrhoea compared to that in our study. In Malta, the rate for infectious intestinal disease was slightly lower than that of ours (3.2\%) (21).

In our study, the highest incidence of acute diarrhoea was observed among young adults aged 2029 years, followed by teenagers (10-19 years), and adults aged 30-39 years. Children aged less than five years had an incidence of acute diarrhoea that was slightly lower than in adults aged $30-39$ years. A similar picture was observed in Queensland where the highest incidence was observed among persons aged 18-39 years, followed by children aged seven months to four years (29). Other studies have found the highest rates among children aged less than five years while the lowest rates were found among persons aged 65 years and above $(10,11,16,28)$. In our study, the lowest incidence rate was observed among children aged 5-9 years, followed by adults aged 50-59 years. A possible reason for the higher incidence of acute diarrhoea among young adults 
compared to other age-groups in our population could be attributed to their lifestyle and eating habits rather than their inherent susceptibility to develop intestinal infections. Being young healthy adults, they are likely to be single and more active and mobile compared to other age-groups. The lifestyle of these adults in the workforce or in higher institutions of learning puts them at a higher risk of exposure to food poisoning and gastroenteritis.

Although the prevalence of acute diarrhoea was higher among females in Norway (12), Canada $(13,14,16,17,19)$, Australia $(15,16)$, Ireland $(16)$, the USA (16), and the Netherlands $(18,20)$, no such finding was found in our study. Other studies in Argentina, the USA, Malta, and Australia also did not find any differences between the sexes $(7,10,11,21,29)$. In Cuba however, males had higher morbidity due to acute gastrointestinal disease than females (8).

Our study found that the Chinese were least likely to report acute diarrhoea compared to other major ethnic groups. Many other studies have shown similar racial or cultural group differences in rates of acute diarrhoea $(11,14,17)$. Although the reasons for such differences are not clear, the finding could be attributed to genetic or sociocultural differences between the races, which may be related to dietary and culinary practices or risk of acquiring gastrointestinal infections. The role of factors, such as genetics, immunity, and sociocultural component, in acquiring foodborne illnesses has been raised before $(30,31)$. Tam highlighted that, although little research has been done on behavioural, societal and cultural practices, these factors, including food choice and availability, consumer and societal attitudes towards food, and food-preparation practices, are part of the epidemiology of foodborne illness (30). In Malaysia, any Chinese cuisine typically is stir-fried, where the food is best served hot from the wok. Food that is thoroughly cooked and eaten immediately thereafter minimizes the risk of food poisoning.

Persons with a secondary or higher level of education were more likely to report acute diarrhoea than persons with no formal education. Similar findings were found in the USA and Queensland $(10,29)$. Other studies in the USA, Canada, and the Netherlands also showed that rates of gastrointestinal diseases increased as the level of education rose $(11,14,18)$. Conversely, in Malta, the majority of cases had a lower level of education (21). Since social disadvantage, which is usually associated with lower levels of education, does not seem to be a risk factor in our study, it is likely that age may be a confounding factor. Young adults with the highest incidence of acute diarrhoea are more likely to have attained higher levels of education compared to older adults. Those with higher levels of education usually also have higher incomes, thus influencing their lifestyle, such as eating and travelling habits, and putting them at a greater risk of acquiring foodborne illnesses (18).

There was no difference in the incidence of acute diarrhoea among the different socioeconomic groups in our study. A similar finding was observed in other studies $(10,14,29)$. In Australia, those with higher socioeconomic status had an increased risk of gastroenteritis (15). Rural residents had a higher incidence of acute diarrhoea compared to urban residents in this study. The finding is similar to that from a Canadian study (19). Elsewhere, studies have found either higher rates in urban rather than rural residents (10) or no difference in rates between urban and rural residents $(11,17,29)$.

After adjusting for confounders, multivariate analyses revealed that only age, ethnicity, educational level, and locality were predictors of acute diarrhoea in the Malaysian population. In studies elsewhere, apart from age, income, gender, season, neighbourhood of residence, and health insurance were also the predictors for gastrointestinal illness $(7,8$, $15,17)$.

The severity of acute diarrhoea in the study was reflected by its mean duration and the presence of other associated symptoms experienced. The overall mean duration of acute diarrhoea in this study - which was two days-was comparable with that from Argentina, Cuba, and the Foodnet studies in the USA $(7,8,10,11)$. It must be cautioned that, in the US studies, acute diarrhoea was defined as self-reported diarrhoea that lasted for more than one day or was associated with impaired daily activity. Using a broader case definition, the average duration of illness in Canada was 3.7 days (14). A higher mean duration was also reported in Malta and Ireland $(21,28)$. While the range of duration for acute diarrhoea in our study was 1-7 days, in Argentina, the USA, and Canada, the range was much longer, lasting for at least four weeks $(7,10,11,14)$. The duration was comparable with findings from studies in Cuba and Ireland $(8,28)$.

Acute diarrhoea, in our study, was mostly associated with abdominal cramps followed by vomiting and fever. The findings concurred with those of the Foodnet study where more than half of the respondents with acute diarrhoea also had abdominal cramps $(10,11)$. In other studies, abdominal 
pain was the most common diarrhoea-associated symptom $(8,16)$. However, unlike our study where almost a similar proportion of the estimated population with acute diarrhoea had fever or vomiting, a higher proportion of respondents had fever rather than vomiting in Cuba and the USA $(8,10,11)$. In Argentina, headache and muscle-pain were the most common secondary symptoms (7). Although there was a seasonal variation in the proportion of associated symptoms observed with acute diarrhoea in the Foodnet study, the trend was similar throughout the different seasons. The differences observed in the proportion of respondents with associated symptoms between the studies could be explained by the different definitions used. The definition for acute diarrhoea used in the Foodnet study implies that these cases were more severe compared to cases of acute diarrhoeal episodes only. Based on the duration and associated symptoms of acute diarrhoea in our study, we can conclude that $>40.0 \%$ of the cases were mildly affected (no associated symptoms) and recovered quickly (within a day).

In Malaysia, it is a requirement by law to notify all new cases of cholera, typhoid, and paratyphoid, all forms of dysentery, and food poisoning. Diarrhoea is the common symptom of all these diseases. During 1990-2006, the number of annual notifications received for the above diseases ranged from 2,934 to 10,416 cases (32). In contrast, our study estimates at least 13 million episodes of acute diarrhoea annually. The figures indicate that acute diarrhoea in Malaysia is grossly under-reported, with only less than $0.1 \%$ of cases being captured by the national surveillance system annually. Under-reporting also occurs elsewhere $(7,33,34)$. Estimates in England noted that only about one in six cases presents to the general practitioner, and of these, only a fraction was notified to the national surveillance system (34). This finding is not unexpected as the majority of the episodes are mild, not warranting medical treatments. Studies have shown that a sizeable proportion of acute diarrhoea can be attributed to food poisoning (35-38). In Malaysia, there is still a vast room for improvement in terms of the level of food hygiene and related practices among food-handlers and the general public. The implications for prevention of acute diarrhoea are significant.

\section{Limitations}

The estimates from the present study have not been adjusted for the differences in the population structure. It has only been weighted to the 2006 projected population. Therefore, the actual burden of acute diarrhoea in the population, in terms of the total number of episodes per year, is likely to be more, assuming that the incidence rate throughout the year remains constant. In reality, seasonal, geographical and sociocultural factors are expected to influence local variations in the incidence of acute diarrhoea in the country throughout the year.

However, the strength of our study lies with its population-based study design, its high response rate, and minimization of recall bias, namely 'telescoping' using a short four-week recall period (34). One limitation of the study is the possibility of an individual experiencing two or more episodes of acute diarrhoea within the four-week recall period but reporting it as a single episode. The importance of using a validated definition for diarrhoea and episodes has been highlighted (39-41). It has also been suggested that three intervening diarrhoea-free days are optimum to define a new episode $(39,40)$. Our definition for duration of acute diarrhoea was non-specific and did not address any intervening diarrhoea-free days.

\section{Conclusions}

This study was the first of its kind in Malaysia, providing baseline estimates for the incidence and distribution of acute diarrhoea among the general population. It highlights that acute diarrhoea is still a major public-health problem in Malaysia, with a four-week incidence of $5 \%$ in the estimated population. The $13,474,728$ episodes of acute diarrhoea per year mostly affected teenagers and young adults. Since these young adults comprise the economically-productive population, efforts for the prevention and management of acute diarrhoea must be focused on this sub-population. Further research is recommended to study the reasons for the age, ethnicity, educational level, and locality differentials in the incidence of acute diarrhoea observed in this study. Understanding how social and cultural factors influence the incidence of acute diarrhoea is fundamental in planning long-term effective control measures.

National targets must be set to reduce the overall incidence of acute diarrhoea. A concerted effort to improve public-health surveillance and notification of the disease must also be made at the same time, if the effectiveness of intervention is to be evaluated. Intermittent population-based studies are recommended to estimate the true burden and compare trends of acute diarrhoea in the general population. 


\section{ACKNOWLEDGEMENTS}

Funding for this research was provided by the Ministry of Health, Malaysia. The authors thank the Director General of the Ministry of Health, Malaysia, for his permission to publish this paper. The authors also thank the members of the National Health and Morbidity Survey 2006 team for making this survey a success.

\section{REFERENCES}

1. Mathers CD, Lopez AD, Murray CJL. The burden of disease and mortality by condition: data, methods and results for 2001. In: Lopez AD, Mathers CD, Ezzati M, Murray CJL, Jamison DT, editors. Global burden of disease and risk factors. New York, NY: Oxford University Press, 2006:45-240.

2. Bern C. Diarrhoeal diseases. In: Murray CJL, Lopez $\mathrm{AD}$, Mathers $\mathrm{CD}$, editors. Global burden of disease and injury series. V. 4. Geneva: World Health Organization, 2004:1-28.

3. Kosek M, Bern C, Guerrant R. The burden of diarrhoeal disease, as estimated from studies published between 1992 and 2000. Bull World Health Organ 2004;81:197-204.

4. World Health Organization. Water, sanitation and hygiene link to health: facts and figures, Geneva: World Health Organization, 2004. 1 p. (http://www. who.int/water_sanitation_health/en/factsfigures 04 . pdf, accessed on 21 March 2011).

5. Shin H, Lee S, Kim JS, Kim J, Han KH. Socioeconomic costs of food-borne disease using the cost-of-illness model: applying the QALY method. J Prev Med Public Health 2010;43:352-61.

6. van den Brandhof WE, De Wit GA, de Wit MA, van Duynhoven YT. Costs of gastroenteritis in the Netherlands. Epidemiol Infect 2004;132:211-21.

7. Thomas MK, Perez E, Majowicz SE, Reid-Smith R, Albil S, Monteverde M et al. Burden of acute gastrointestinal illness in Galvez, Argentina, 2007. J Health Popul Nutr 2010;28:149-58.

8. Aguiar Prieto P, Finley RL, Muchaal PK, Guerin MT, Isaacs S, Dominguez AC et al. Burden of self-reported acute gastrointestinal illness in Cuba. J Health Popul Nutr 2009;27:345-57.

9. Majowicz S, McNab W, Sockett P, Henson S, Dore K, Edge $\mathrm{V}$ et al. Burden and cost of gastroenteritis in a Canadian community. J Food Prot 2006;69:651-9.

10. Herikstad H, Yang S, Gilder TV, Hadler J, Blake P, Deneen $\mathrm{V}$ et al. A population-based estimate of the burden of diarrhoeal illness in the United States: FoodNet, 1996-1997. Epidemiol Infect 2002;129:9-17.
11. Imhoff B, Morse D, Shiferaw B, Hawkins M, Vugia D, Lance-Parker S et al. Burden of self-reported acute diarrhoeal illness in FoodNet surveillance areas, 19981999. Clin Infect Dis 2004;38(Supp 3):S219-26.

12. Kuusi M, Aavitsland P, Gondrosen B, Kapperud G. Incidence of gastroenteritis in Norway-a populationbased survey. Epidemiol Infect 2003;131:591-7.

13. Majowicz SE, Dore K, Flint JA, Edge VL, Read S, Buffett MC et al. Magnitude and distribution of acute, self-reported gastrointestinal illness in a Canadian community. Epidemiol Infect 2004;132:607-17.

14. Thomas MK, Majowicz SE, MacDougall L, Sockett PN, Kovacs SJ, Fyfe M et al. Population distribution and burden of acute gastrointestinal illness in British Columbia, Canada. BMC Public Health 2006;6:307.

15. Hall GV, Kirk MD, Ashbolt R, Stafford R, Lalor K. Frequency of infectious gastrointestinal illness in Australia, 2002: regional, seasonal and demographic variation. Epidemiol Infect 2006;134:111-8.

16. Scallan E, Majowicz SE, Hall G, Banerjee A, Bowman CL, Daly L et al. Prevalence of diarrhoea in the community in Australia, Canada, Ireland, and the United States. Int J Epidemiol 2005;34:454-60.

17. Majowicz SE, Horrocks J, Bocking K. Demographic determinants of acute gastrointestinal illness in Canada: a population study. BMC Public Health 2007;7:162.

18. de Wit MA, Koopmans MP, Kortbeek LM, Wannet WJ, Vinje J, van Leusden F et al. Sensor, a population-based cohort study on gastroenteritis in the Netherlands: incidence and etiology. Am J Epidemiol 2001;154:666-74.

19. Sargeant JM, Majowicz SE, Snelgrove J. The burden of acute gastrointestinal illness in Ontario, Canada, 2005-2006. Epidemiol Infect 2008;136:451-60.

20. Hoogenboom-Verdegaal AM, de Jong JC, During M, Hoogenveen R, Hoekstra JA. Community-based study of the incidence of gastrointestinal diseases in the Netherlands. Epidemiol Infect 1994;112:481-7.

21. Gauci C, Gilles H, O'Brien S, Mamo J, Stabile I, Ruggeri FM et al. The magnitude and distribution of infectious intestinal disease in Malta: a populationbased study. Epidemiol Infect 2007;135:1282-9.

22. Zuridah H, Kirkwood CD, Bishop RF, BogdanovicSakran N, Yap KL. Molecular characterization and epidemiology of rotavirus isolates obtained from children with diarrhoea in Malaysia. Med J Malaysia 2009;64:193-6.

23. Hsu VP, Abdul Rahman HB, Wong SL, Ibrahim LH, Yusoff AF, Chan L et al. Estimates of the burden of rotavirus disease in Malaysia. J Infect Dis 2005;192(Suppl 1):S80-6.

24. Hung LC, Wong SL, Chan LG, Rosli R, Ng AN, Bresee JS. Epidemiology and strain characterization of rota- 
virus diarrhea in Malaysia. Int J Infect Dis 2006;10:4704.

25. Yap KL, Yasmin AM, Wong YH, Ooi YE, Tan SC, Jegathesan $\mathrm{M}$ et al. A one year community-based study on the incidence of diarrhoea and rotavirus infection in urban and suburban Malaysian children. Med J Malaysia 1992;47:303-8.

26. Institute for Public Health. The third national health and morbidity survey (NHMS III) 2006. V. 1. Kuala lampur: Institute for Public Health, Ministry of Health Malaysia, 2008:1-9.

27. SPSS Inc. Statistical package for social sciences. Version 16. Chicago, IL SPSS Inc., 2007.

28. Acute gastroenteritis in Ireland, North and South. A telephone survey. 2003. (http://www.safefoodonline. com/article.asp? article $=434$, accessed on 7 October 2010).

29. Ozfoodnet. A survey of community diarrhoeal illness among adults and young children in Queensland. Queensland: Queensland OZFOODNET Communicable Diseases Unit, Queensland Health, 2002. (http://www.ozfoodnet.gov.au/internet/ ozfoodnet/publishing.nsf/Content/7BDEF9F8 EC3835D9CA257165001AB31D/\$File/fbi_survey_ report_2002.pdf, accessed on 13 April 2010).

30. Tam CC. Fortune and foreigners: toward an epidemiology of food (borne illness). Epidemiology 2008;19:291-3.

31. King JC, Black RE, Doyle MP, Fritsche KL, Halbrook $\mathrm{BH}$, Levander OA et al. Foodborne illnesses and nutritional status: a statement from an American Society for Nutritional Sciences Working Group. J Nutr 2000;130:2613-7.

32. Incidence of notifiable communicable diseases in Malaysia for 1990-2006. (http://www.dph.gov.my/ survelans, accessed on 24 November 2009).
33. MacDougall L, Majowicz S, Dore K, Flint J, Thomas K, Kovacs $\mathrm{S}$ et al. Under-reporting of infectious gastrointestinal illness in British Columbia, Canada: who is counted in provincial communicable disease statistics? Epidemiol Infect 2008;136:248-56.

34. Wheeler JG, Sethi D, Cowden JM, Wall PG, Rodrigues LC, Tompkins DS et al. Study of infectious intestinal disease in England: rates in the community, presenting to general practice, and reported to national surveillance. The Infectious Intestinal Disease Study Executive. BMJ 1999;318:1046-50.

35. Hall G, Kirk MD, Becker N, Gregory JE, Unicomb L, Millard G et al. Estimating foodborne gastroenteritis, Australia. Emerg Infect Dis 2005;11:1257-64.

36. Mead PS, Slutsker L, Dietz V, McCaig LF, Bresee JS, Shapiro C et al. Food-related illness and death in the United States. Emerg Infect Dis 1999;5:607-25.

37. Kuchenmuller T, Hird S, Stein C, Kramarz P, Nanda A, Havelaar AH. Estimating the global burden of foodborne diseases-a collaborative effort. Euro Surveill 2009;14(18):pii:19195.

38. Flint JA, Van Duynhoven YT, Angulo FJ, DeLong SM, Braun P, Kirk M et al: Estimating the burden of acute gastroenteritis, foodborne disease, and pathogens commonly transmitted by food: an international review. Clin Infect Dis 2005;41:698-704.

39. Morris SS, Cousens SN, Lanata CF, Kirkwood BR. Diarrhoea-defining the episode. Int I Epidemiol 1994;23:617-23.

40. Baqui AH, Black RE, Yunus M, Hoque AR, Chowdhury HR, Sack RB. Methodological issues in diarrhoeal diseases epidemiology: definition of diarrhoeal episodes. Int J Epidemiol 1991;20:1057-63.

41. Majowicz SE, Hall G, Scallan E, Adak GK, Gauci C, Jones TF et al. A common, symptom-based case definition for gastroenteritis. Epidemiol Infect 2008;136:88694. 